\title{
NOVA RAZVOJNA STRATEGIJA POKRAJINSKO HOMOGENIH OBROBNIH OBMOČIJ SLOVENIJE
}

\section{Marijan M. Klemenčič}

Oddelek za geografijo, Filozofska fakulteta, Univerza v Ljubljani, Aškerčeva 2, SI-I000 Ljubljana

e-mail: marijan.klemencic@guest.arnes.si

Izvirni znanstveni članek

COBISS 1.01

\section{Izvleček}

Prispevek predstavlja celovit pristop k razvoju obrobnih, pokrajinsko homogenih območij. Nakazane so slabosti dosedanjih pristopov reševanja nerazvitih območij

Ključne besede: Razvojna strategija, obrobna območja, upravna razdelitev, Slovenija.

\section{NEW DEVELOPMENT STRATEGY OF THE PERIPHERAL LANDSCAPE HOMOGENIOUS AREAS IN SLOVENIA}

\begin{abstract}
The contribution presents comprehensive approach to development of peripheral homogenous areas. The article indicates weakness of previous approaches towards solutions of undeveloped areas.
\end{abstract}

Key words: Development strategy, peripheral area, administrative division, Slovenia. 


\section{UVOD}

Slovensko ozemlje je splet številnih pokrajinsko homogenih enot, ki doživljajo različne razvojne usode. Večina tistih, ki so na robu državnega ozemlja, je poznanih kot nerazvita in na določen način odpisana območja. Dosedanji razvojni koncepti sicer izražajo potrebo po zmanjšanju razvojnih razlik med slovenskimi pokrajinami, dejansko pa so razvojna prizadevanja usmerjena na osrednja območja. Na splošno se v Sloveniji razvojni pristopi premalo naslanjajo na poznavanje zakonitosti družbenogospodarskega in prostorskega razvoja ter zato podlegajo tehnokratskemu načinu razmišljanja in trenutnemu stanju v pokrajini. Učinkovitega načrtovanja ne more biti brez vizije razvoja, ki pa mora izhajati iz dobrega poznavanja stanja $\mathrm{v}$ pokrajini in splošnih razvojnih trendov gospodarsko razvite družbe. Številni dosedanji razvojni programi (bolje projekti) so bolj izraz strokovnega lartpurlartizma, izživljanja posameznih strok na lokalnih posebnostih (običaji, kulinarične, arhitektonske, kulturne, tehnične in naravne posebnosti), zanemarjen pa je bistveni del, to je gospodarski. Sedanja močno centralizirana razvojna politika je v veliki meri "prostorska sociala", potrebna pa bi bila "prostorska aktivizacija/animacija".

V razpravi želimo opozoriti na celovit pristop k razvoju obrobnih, pokrajinsko homogenih pokrajin v Sloveniji, ki bi ustrezal zahtevam sodobne družbe. Pokrajinska homogenost je izpostavljena zaradi razvojnih možnosti, ki jih ponuja lokalna identiteta. Predlagamo celovit razvojni concept za obrobne pokrajine, ki so potisnjene na rob širšega družbenogospodarskega razvoja, torej izven dosega državnih razvojnih programov in učinkovitih razvojnih posegov gospodarsko šibkih občin.

\section{OPREDELITEV PROBLEMA}

Od 70. let 20. stoletja se slovenska strokovna javnost in politika resno ukvarjata s pojavom tako imenovanih nerazvitih območij. Med takšna spadajo območja, ki ležijo na robu živahnejših gospodarskih dogajanj in zato zaostajajo v razvoju. V zakonodaji so bila ta območja različno poimenovana, pri njihovi opredelitvi pa upoštevani različni kriteriji (Benkovič, 2003), ki jih po časovnem zaporedju jih lahko razdelimo na tri skupine:

1. manj razvita območja (demogeografski, ekonomski in infrastrukturni kazalci);

2. demografsko ogrožena območja (demografski kazalci);

3. območja s posebnimi razvojnimi problemi (ekonomski kazalci).

Značaj kazalcev je nakazoval načine reševanja manjše razvitosti. Ukrepi za odpravo (pre)velikih razlik v razvitosti so bili nezadostni in niso prinesli željenih učinkov.

Izhodišča za opredeljevanje in reševanje slabše razvitosti so bila zelo preprosta. Slovenijo se je obravnavalo kot homogen družbenogospodarski prostor, znotraj katerega so bila po območjih različna odstopanja od povprečne razvitosti, opredeljena z ekonomskimi kazalci (strukturni demografski problemi so bili le del gospodarske strukture). Takšen pristop je izhajal iz takratne slovenske stvarnosti, ki je bila (pretirano) vpeta v industrializacijo. 
Z upoštevanjem širših strukturnih problemov v začetku 21. stoletja po vzoru evropskih pristopov je bila vsaj posredno nakazana posebnost posameznih pokrajin in s tem možnost specifičnega reševanja slabše razvitosti. Regionalne razvojne agencije naj bi poskrbele za razvoj ožjih območij, pri čemer pa so zaradi različnih vzrokov (sektorskega pristopa, pomanjkanja denarja, znanja, organiziranosti, idej) le malo uspešne. Temeljna slabost dela agencij je v vztrajanju pri industrijski razvojni paradigmi in torej premajhnem upoštevanju zahtev sodobne družbe in lokalnih razvojnih potencialov.

\section{POSTINDUSTRIJSKA DRUŽBA IN PROSTORSKI RAZVOJ}

Suburbanizacija in novejše vračanje dela mestnega prebivalstva na podeželje sta prostorska kazalca novih trendov v slovenski družbi. Razvoj prometa in informacijske tehnologije omogočata nov poselitveni vzorec, za katerega se je uveljavil izraz koncentrirana dekoncentracija. Poleg tega se s povečanjem prostega časa in zviševanjem življenjskega standarda razvija nov način življenja, ki pomembno vpliva na razvoj pokrajine. Težnja po bivanju in gibanju v naravnem okolju je vse izrazitejša. Motivi preživljanja prostega časa so vse bolj različni, kar prispeva $\mathrm{k}$ vse pestrejši ponudbi storitev in $\mathrm{s}$ tem $\mathrm{k}$ večjim preživetvenim možnostim domačega prebivalstva. Pestrost in prilagodljivost ponudbe storitev sta temelja imperativa sodobne družbe. Pokazalo se je, da imajo globalizacijske težnje, ki so se še pred kratkim zdele vsemogočne, nalomljena krila. Lokalne/regionalne posebnosti pridobivajo na pomenu. Za uveljavljanje teh posebnosti pa je potrebno aktivirati notranje razvojne potenciale. Industrijska doba jih je na žalost v veliki meri osiromašila in marsikje skoraj uničila, zato za njihovo uveljavljanje potrebujejo zunanjo (državno, regionalno) pomoč.

C̆e je način organizacije prostora $\mathrm{v}$ agrarni dobi povsem nasproten tistemu $\mathrm{v}$ dobi industrializacije (Klemenčič M. M., 2003), pa je postindustrijska družba v agrarnem načinu poselitve našla kar nekaj ugodnosti:

- razpršena poselitev omogoča uresničitev želja številnih Slovencev, da bi imeli lasten dom $\mathrm{z}$ vrtom v čim manj pozidanem okolju;

- $\quad$ stik z naravo, kar je vse bolj cenjena vrednota;

- podeželske skupnosti z občutkom solidarnosti in druženja. Doseljenci, ki se ne želijo vključiti v krajevno skupnost, nemoteno lahko živijo v svojem socialnem okolju;

- kulturno-etnografske vrednote, kot so tip pokrajine, stara kmečka arhitektura, običaji, stare obrti, itn. povečujejo kakovost življenja.

Temeljni pogoj za vključitev doseljencev v podeželsko okolje je njegova živost, ki vključuje ugodno demografsko stanje, oskrbo in infrastrukturo in zlasti vzdrževanje kulturne pokrajine.

Pokrajinska homogenost je v agrarni dobi pogojevala enotno gospodarsko usmerjenost in s tem posebnost $\mathrm{v}$ odnosu do drugih pokrajin. Možnost prodaje kmetijskih pridelkov in izdelkov ter nudenja storitev so omogočili specializirano proizvodnjo in $\mathrm{s}$ tem še povečali prepoznavnost pokrajine. Posebnost in prepoznavnost ponudbe sta dejstvi, ki se v sodobni družbi kažeta kot pomembna razvojna dejavnika. 


\section{NOVA PODOBA PERIFERNIH OBMOČlJ}

Družbenogospodarske spremembe, ki jih je povzročila industrializacija na obrobnih območjih, se kažejo popolnem razkroju agrarnega gospodarstva in izčrpanosti demografske strukture. Skromno kmetovanje je namenjeno le samosokrbi, zaraščanje kmetijskih površin je vsesplošno. Doma je ostalo ostarelo in manj podjetno, nemobilno prebivalstvo.

Postindustrijsko obdobje tudi na obrobna območja prinaša spremembe. Počitniške hiše iz industrijskega obdobja so izjemen pojav, zato pa se nekako v zadnjem desetletju marsikatera vaška hiša spreminja $v$ bivališče, ki je različno dolgo in pogosto obljudeno: ob koncu tedna, med dopusti/počitnicami, v toplem delu leta, ali pa celo trajno. Tudi obrobna območja doživljajo vračanje domačinov, praviloma ostarelih. Demografska in gospodarska slika območij je postala zelo pestra, saj gre za srečevanje dveh svetov: starega agrarnega in novega postindustrijskega. $\mathrm{Na}$ žalost pa so predstavniki obeh svetov ostareli, socialno in gospodarsko šibki. Temu primerna je družbena infrastruktura: redke šole delujejo pod grožnjami zaprtja, zdravstvena oskrba je simbolična, vedno bolj problematična je tudi duhovna oskrba. Posebno vračajoče prebivalstvo se zaveda vrednot in posebnosti domače pokrajine, ki bi jih lahko izkoristili v razvojne namene. Sem ter tja se kot skromni otočki pojavljajo poskusi novih dejavnosti (vzreja divjadi, kmečki turizem, sadjarstvo itn.) in obujanje starih (na primer žganjekuha, konzerviranje živil, predelava mesa in mleka, obdelava lesa). Manjkata ugodna družbenogospodarska klima in dejavniki, ki bi posamezne razvojne "lučke" povezali v učinkovit razvojni "kres".

\section{POKRAJINSKA PESTROST KOT RAZVOJNI DEJAVNIK}

Čeprav je bil družbenogospodarski razvoj Slovenije v preteklosti v primerjavi z zahodnoevropskimi državami neugoden (močno zaostajanje industrializacije, politično vodenje gospodarstva po drugi svetovni vojni), pa ima danes Slovenija pred njimi marsikatero prednost. Ena izmed njih je posledica omenjenega preteklega razvoja, ki je predvsem z neekonomsko politiko do kmetijstva v veliki meri ohranil naravno okolje. Spremljevalec takšnega razvoja ali pogojno pasivni razvojni dejavnik pa je pestra pokrajinska struktura Slovenije. Razvojna politika se ji mora prilagoditi, če želi biti učinkovita. Industrializacija je abstrahirala pokrajinsko različnost in postavila $\mathrm{v}$ ospredje prometno dostopnost, torej dajala prednost ravninskim in dolinskim predelom. Z novo razvojno stopnjo družbe pridobivajo na pomenu ravno tista območja, ki jih je doba industrializacije zanemarjala.

Slovenska pokrajina ponuja praktično neomejeno število razvojnih možnosti. V pestrosti pokrajin je njena posebna moč. Na videz podobne pokrajine so med seboj zelo različne. Je več podobnosti ali razlik v pokrajinski, demografski, gospodarski, zgodovinski, identitetni sliki in geografskem položaju med Vzhodnim, Zahodnim in Severovzhodnim predalpskim hribovjem? Ali med Halozami in Brkini? Ali med Podpohorskimi goricami in gorjanskim Podgorjem? Pa med Goriškimi Brdi in Lendavskimi goricami? Kje v Sloveniji je dolina, ki bi bila podobna Mežiški? Ali kotlina Bohinju? Nadaljevanje brez konca. Različnost ponuja pokrajinam različnost razvoja prek različnosti ponudbe. 
Ničkolikokrat izrečena in napisana resnica o bogastvu, ki ga predstavlja pokrajinska pestrost, se praksa temu bogastvu odreka. Lokalna območja praviloma izpostavljajo svoje posebnosti, a za celovitejši razvoj jim zmanjka moči. Pobudniki razvoja so običajno posamezni navdušenci ali ozek krog ljudi, ki pa nimajo zadosti finančnih sredstev, kadrov in organizacijskih izkušenj, zaradi česar rezultati naporov ostanejo pri predstavitvah etnografskih posebnostih. $\mathrm{Na}$ drugi strani gredo centralizirano vodeni razvojni programi mimo učinkovitega reševanja razvojnih problemov obrobnih pokrajin, ker ne vključujejo lokalnega prebivalstva, njihovih potreb, zmožnosti in interesov kot izhodiščnega in končnega subjekta razvojnih programov. Namesto da bi se potrebe in načini njihovega reševanja stikali, hodijo drug mimo drugega.

Centralistično (državno) usmerjeni razvojni programi imajo torej dvojno temeljno pomanjkljivost, ki že v izhodišču preprečujeta njihovo uspešno izpeljavo. Prva je zgrešen razvojni koncept, druga pa domačemu prebivalstvu in problemom odtujen način izvedbe.

\section{UPRAVNA RAZDELITEV KOT RAZVOJNI (NE)DEJAVNIK}

Občina je sicer suveren na svojem območju, a praviloma prešibka za učinkovit razvoj, zlasti obrobnih predelov. Praksa kaže, da kadrovska usposobljenost občinskih uprav zadošča le za reševanje komunalnih in infrastrukturnih problemov, za uspešno reševanje razvojnih vprašanj pa so strokovno prešibke, premalo seznanjene z možnostmi različnih virov (so)financiranja razvojnih projektov ter okorne pri lobiranju. Našteti razlogi jasno kažejo, da je povezovanje občin pri reševanju širših prostorskih problemov nujno potrebno.

Stopnja razvoja se meri s statističnimi kazalci v okviru občin. Brez vrhunskega strokovnega znanja lahko ugotovimo, da je takšen pristop v slovenskih razmerah izrazito formalističen in zavajujoč, daleč od resničnega prostorskega stanja. Obravnavane obrobne pokrajine so namreč redko poseljene, zato bistveno ne vplivajo na vrednost kazalcev. "Brkinske" občine imajo lahko statistične kazalce ugodne, Brkini pa $\mathrm{v}$ resnici gospodarsko in prebivalstveno propadajo.

Demografska kriza Slovenije je tako globoka, da je stagnacija števila prebivalstva pomemben razvojni dosežek nekega območja. Kaj pa obrobna območja? Zaradi demografske izčrpanosti je v razvojne projekte nujno potrebno vključiti vračajoče prebivalstvo, stalno ali občasno prisotno.

Občinske uprave naj bi poleg osnovne infrastrukturne in oskrbne opremljenosti zagotavljale tudi pogoje, ki bi prebivalstvu omogočili kar najboljši bivalni in življenjski standard. Čeprav so občinske politike v načelu razvojno usmerjene, pa so njihovi učinki zelo različni vsaj na dveh ravneh: na ravni celotne občine in na njenih posameznih delih. Učinek kopičenja ne velja le za velike prostorske sisteme, ampak tudi za lokalne razmere. Središčna območja so torej že po naravi stvari v prednostnem položaju nasproti obrobnim območjem. To je toliko izrazitejše, kolikor večja je občina.

Sintagma: "obstoj občine je v načelu koristen za družbenogospodarski in prostorski razvoj nekega območja" nakazuje razvojne (ne)ovire obrobnih območij. Oglejmi si tri vzorčne pokrajine: Brkine, Haloze in Goričko. 
Brkini so razdeljeni med štiri občine: divaško, pivško, hrpeljsko-kozinsko in ilirskobistriško. Slednja obsega dobro polovico Brkinov, medtem ko si ostale občine delijo le manjša območja. V razvojnem pogledu lahko Brkine opredelimo kot "nikogaršnje ozemlje"; vsem prizadetim občinam so Brkini funkcijsko in prostorsko le obroben problem. Vse občine imajo gospodarsko in prebivalstveno težišče izven hribovja, ki jim pomeni le razvojno breme. Potrebna velika vlaganja (finančna, kadrovska, organizacijska) ne bi imela hitrih povratnih učinkov, zato Brkini ostajajo na občinskih seznamih območij, zanimivih za vlaganja, stalno na zadnjem mestu.

Haloze so v podobnem položaju kot Brkini; nekaj boljši formalni položaj jim daje občina Zavrč, ki je v celoti na haloškem območju ter občini Videm in Majšperk, ki imata večino občinskega ozemlja v Halozah. Del Haloz vključujeta še občini Gorišnica na vzhodu in Slovenska Bistrica na zahodu. Vse naštete občine, razen slovenjebistriške, ki je prevelika, da bi se močneje zanimala za obrobni haloški del, so gospodarsko šibke in s težiščem v ravninskem in dolinskem svetu.

Goričko ima povsem drugačen značaj. Veliko večino ozemlja pokrivajo "domače" občine, kar naj bi bil razvojno ugoden dejavnik. Problem je poleg gospodarske šibkosti občin pomanjkanje nosilnega središča, preko katerega bi lahko učinkoviteje potekalo usmerjanje razvoja Goričkega. Razvojna problematika območja je posebno občutljiva v narodnostnem pogledu. Sodelovanje občin z gospodarsko močnejšim sosedstvom v Avstriji in na Madžarskem lahko pripelje do slabitve slovenstva in do slabitve celovite razvojne politike. Zemljiški nakupi tujcev, ki očitno potekajo neusmerjeno, so dober kazalec pomanjkanja vsklajenosti pri razvoju Goričkega.

S podobnimi težavami kot vzorčna območja se ubadajo tudi ostale obrobne pokrajine: "razcepljena" (na dve občini) Suha krajina, "razbito" (na več občin) Kozjansko, kjer ima krajinski park bolj kot ne vlogo "pleskarja razpadajočih fasad”, območje Kozjaka, Krasa in druga.

\section{CELOVIT RAZVOJNI PRISTOP}

Nove družbene razmere zahtevajo temeljit preobrat načina razmišljanja načrtovalcev razvoja in preoblikovanje (prilagoditev) dosedanjega pristopa $\mathrm{k}$ družbenogospodarskemu in prostorskemu načrtovanju. V nasprotju s sedanjim pristopom, ki temelji na krepitvi centralnih krajev kot nosilcev razvoja njihovega zaledja, bi se morali na obrobnih območjih na lokalni ravni kot izhodišče izpostaviti pokrajinski razvojni potenciali. Ali drugače: namesto dosedanjega koncepta, po katerem v praksi zaledje služi centralnemu kraju, bi moral centralni kraj služiti zaledju. Splošno uveljavljeno teoretično načelo sistema centralnih krajev izgubi svojo veljavnost $\mathrm{v}$ primeru, ko je zaledje centralnega kraja toliko osiromašeno, da ne more več aktivno sodelovati na relaciji centralni kraj - zaledje oziroma ko v podsistemu entropija doseže (pre)visoko vrednost. Takšni primeri so najbolj izraziti na lokalni ravni. Da se ponovno vzpostavi delovanje (lokalnega) podsistema, morajo obrobna območja postati subjekt razvoja, kar je na pokrajinsko homogenih območjih najlaže doseči z razvojem pokrajinske prepoznavnosti (identitete). Ni zadosti, da se izpostavi in razvija le en lokalni produkt, ki dobi tržno razpoznavnost, pač pa se mora razvijati celotno gospodarstvo v okviru enotne (lokalne/ pokrajinske) razpoznavnosti. 
Način reševanja razvojnih problemov naj bi bil organizacijsko čim bolj prilagodljiv, podjetniško naravnan in naj bi vključeval strokovnjake $\mathrm{z}$ različnih področij ter predstavnike oblasti vseh stopenj, od lokalne do državne. Sodelovanje udeležencev razvojnih programov naj bi bilo čim manj formalizirano in usmerjeno na izpeljavo konkretnih nalog.

Pri novem razvojnem konceptu sedanji, statično, centralistično in birokratsko vodeni načini izvajanja razvojnih programov ne morejo biti uspešni. Novi pristop zahteva neposredno soočanje z razvojnimi problemi, torej s prebivalci in s pokrajino.

\section{MOBILNOST PROTI STATIČNOSTI}

Marsikje so se mali podjetniki znali prilagoditi novim razmeram tako, da so organizirali potujoče prodajalne, kar pa na žalost nima toliko razvojne kot pa socialno funkcijo. Na Finskem so potem, ko so s konceptom države blaginje zašli v preveliko obremenitev državnega proračuna, iskali gospodarnejše oblike zagotavljanja družbenega standarda tudi prebivalcem na odročnih območjih (Pyy, Lehtola, 1996). Poleg privatizacije storitev in uvajanja prostovoljnega dela, so marsikje namesto tehnično in kadrovsko dobro opremljenih stacionarnih ustanov (na primer na področju zdravstva in socialnega skrbstva) organizirali mobilne ekipe, ki obiskujejo teren in prebivalcem nudijo celovito oskrbo. V osilniški občini na primer so se odločili za obratno pot: ostarele bolne osebe vozijo na zdravstveno postajo. Sicer hvalevreden občinski ukrep, ki pa pomeni le lajšanje socialne nemoči ostarelega prebivalstva in hkrati uveljavljanje sicer nedeklariranega načela, da so ljudje zaradi zdravstva in ne obratno.

$\mathrm{Z}$ mobilnim pristopom bi bilo možno organizirati širše delovanje razvojnih centrov na lokalni ravni. Ekipa strokovnjakov z različnih področij bi nudila strokovne storitve na terenu v okviru dobro premišljenega razvojnega programa. S svojim delom bi lahko pokrivala več območij. Terenski pristop je upravičen in nujen iz večih razlogov:

- obrobno podeželje je demografsko izčrpano;

- $\quad$ izobrazbena raven prebivalstva je nizka;

- podjetniške iniciative posameznikov ostajajo neuresničene zaradi občutka nemoči kot posledica socialne in prometne odmaknjenosti od vitalnih območij (središč);

- $\quad$ izpeljati bi bilo možno dolgoročno oživitev gospodarstva, temelječega na pokrajinskih posebnostih s poudarjenim oblikovanjem lokalne identitete;

- oživljajoče pokrajine bi postale privlačnejše za ohranjanje poselitve $\mathrm{z}$ domačim in doseljenim prebivalstvom.

Vsak razvojni program mora izhajati iz potreb in želja domačega prebivalstva, kar pomeni, da strokovnjaki niso nosilci, ampak nujni pomočniki pri izpeljavi programa.

\section{LOKALNOST IN GLOBALNOST}

Posebno v gospodarskih krogih je uveljavljen pogled, da se je za učinkovit razvoj potrebno na vse načine vključiti v (konkurenčne) globalne gospodarske tokove in da se ne smemo omejevati/zapirati v lokalne okvire (razvojne žepe). 
Slovenija kot celota $\mathrm{v}$ globalnem okviru predstavlja lokalno skupnost z razvitim komplementarnim gospodarstvom (M. M. Klemenčič, 1999). Takšna gospodarska struktura ima dvojno nalogo: najti ustrezno mesto v globaliziranem gospodarstvu in znotraj države razvijati lokalno gospodarstvo.

Vulgarni gospodarski globalizem ne more zadostiti razvojnim potrebam na vseh ravneh, od lokalne do državne, pa tudi ne pokriti vsega povpraševanja. Številne tržne niše ostajajo na voljo drobnim lokalnim proizvajalcem, posebno na področju kakovostne in specifične ponudbe. $\mathrm{Na}$ državni ravni lokalno gospodarstvo je v slovenskih, pokrajinsko in družbenogospodarsko raznolikih razmerah tisto, ki ponuja bogate razvojne možnosti. Seveda pa se nobena lokalna skupnost ne more izolirati od najširših gospodarskih tokov. Potrebno je najti primerno ravnotežje med gospodarstvom, usmerjenim na globalni trg in tistim, ki je usmerjeno na notranje trge. Razmerje med obema vrstama gospodarstva je po pokrajinah lahko zelo različno: gospodarstvo za notranji trg je lahko le dopolnilo globalnemu, lahko pa prevladujoča vrsta gospodarstva. Globaliziran del gospodarstva je veliko bolj občutljiv na širše gospodarske spremembe kot pa lokalni. Neugodnost globaliziranega gospodarstva na obrobnih območjih je tudi v tem, da so njegovi nosilci tujci (nedomačini), ki sledijo le (kratkoročnim) finančnim učinkom. Učinkovit razvojni koncept naj bi torej slonel na domačih podjetnikih oziroma na uravnoteženem deležu gospodarstva za globalni in domači trg.

\section{KOMENTAR}

Predlagani pristop $\mathrm{k}$ vzpodbujanju razvoja obrobnih, posebno pokrajinsko homogenih območij, se morda zdi idealističen ali cello utopičen. Na tak način ga lahko ocenjujemo, če gledamo nanj z vidika dosedanje načina družbene organiziranosti, ki je tog in birokratski. Zahodna družba je že pred desetletji stopila na pot racionalnega načina reševanja družbenih problemov $\mathrm{z}$ vključevanjem pobud civilne družbe in $\mathrm{z}$ različnimi oblikami partnerstva $\mathrm{s}$ privatnim sektorjem. Posebno pomembno pa je dejstvo, da je razvila učinkovit način nadzora nad izvajanjem razvojnih programov.

Predlagani pristop, po katerem naj bi se obrobne pokrajine celovito vključile v sodobni družbenogospodarski in prostorski razvoj Slovenije, ima torej še drugo, prav tako pomembno nalogo: vplivati na spremembo načina razmišljanja in ravnanja državnih ustanov in prek njih tudi ostalih področij družbenega življenja. Za učinkovito reševanje družbenih problemov mora politika sestopiti z državno-centralističnega piedestala in se približati življenjskim problemom. Država, ki je tradicionalno nosilka moči in odločanja, naj postane družbeni servis v najširšem pomenu beside.

Cilj novega pristopa je (p)oživiti življenje v odmaknjenih pokrajinah na način, ki bo uspešno odgovarjal izzivom nove dobe. Na osnovi pokrajinske razpoznavnosti (identitete) naj bi se razvil lokalni družbenogospodarski in prostorski podsistem, ki bi s svojo (novo) privlačnostjo pritegnil zanimanje "domačih" občin. V našem primeru ne gre za klasične razvojne projekte, ampak za subtilen pristop, ki bi ga v medicinskem jeziku lahko označili kot postopek zdravljenja in rehabilitacije bolnika. Prebivalstvu je potrebno obuditi in okrepiti samozaupanje tudi s tem, da se jim nudi stalna in vsestranska podpora. Le na tak način se bodo prebudile življenjske sile, ki edine zagotavljajo dolgoročni obstoj poselitve neke pokrajine. 


\section{Literatura}

Benkovič, M., 2003: Strukturni problemi depopulacijskih območij v Sloveniji. Magistrsko delo. Oddelek za geografijo, Filofoska fakulteta, Univerza v Ljubljani.

Klemenčič, M. M., 1999: Slovenija v globalizacijski pasti. Dela 14, 45-52.

Klemenčič, M. M., 2003: Civilizacijske razvojne stopnje in razvojni problemi obrobnih območij v Sloveniji. Dela 19, 153-164.

Pyy, I., Lehtola, I., 1996: Nordic welfare state as rural policy. V: New rural policy. Finnish journal of rural research and policy. English supplement, vol. 3, 17-34.

\section{NEW DEVELOPMENT STRATEGY OF THE PERIPHERAL, LANDSCAPE HOMOGENIOUS AREAS IN SLOVENIA}

\section{Summary}

Intensive industrialization caused that the areas of Slovenia are strongly differentiated by degree of the socio-economic development. The peripherial areas as the areas along the state border characterized by unfavourable natural conditions (hilly and mountain areas, carst plateaus) being out-of-the-way have been remainded outside the prevailed economic development. Affected by exodus they lost the economic vitality; local identity deriving from the ancient agrarian age, remains the only sign of their existence.

From the 70's remote areas have been defined by the government to give them special support. The policy of the remote areas development have not had many success for the sake of bureaucratic and centralized way of implementation of the measures, mainly limited at some isolated projects.

Proposed strategy of the integrated (and effective) economic and spatial development of the peripheral areas is based upon two main measures:

- using the local sources on the base of local identity;

- giving an integral development assistance.

The smallest central places are not able to take care of development of their hinterland as the areas are scarsely populated, demographically and economically exhausted. Division of natural homogenous regions among some communes represents another important problem; economically weak communes can not be an actor of region's revitalization. Direct assistance should be needed to the peripherial areas by the teams of different field's experts (researchers, managers, representatives of local and state administration) functioning coordinatively. The activity of the experts should be focused on the most urgent problems, needs and interests of the local population; the mobile groups of experts close connected to the field problems seems to be the most efficacious way of the assistance to the local population. The final goal of the strategy is to qualify the peripherial areas for self-dependent development. 